\title{
As pesquisas sobre turismo, hospitalidade e lazer submetidas ao sistema de revisão ética de pesquisas com seres humanos no Brasil
}

\section{Research on tourism, hospitality and leisure submitted to the Brazilian human research ethics review system}

\author{
Ricardo de Oliveira Rezende (REZENDE, R. de O.) ${ }^{*}$
}

RESUMO - Este artigo surgiu de um questionamento acerca do conhecimento e utilização do Sistema CEP/CONEP - Comitê de Ética em Pesquisa/Comissão Nacional de Ética em Pesquisa pelos docentes e discentes dos cursos de pós-graduação em turismo, hospitalidade e lazer. Eis o resultado. Trata-se de um artigo em que se buscou analisar as pesquisas cujo tema fosse o turismo, a hospitalidade e o lazer e que se submeteram a análise ética para pesquisas com seres humanos no âmbito do Sistema CEP/CONEP por meio do sistema Plataforma Brasil. Em primeiro lugar, descobriu-se que os protocolos das áreas escolhidas representavam uma baixa porcentagem em relação à totalidade dos protocolos submetidos; em segundo lugar, identificou-se que havia subtemas mais recorrentes em cada uma das três áreas escolhidas para análise. Além disso, examinou-se que os cursos de mestrado profissional, mestrado e doutorado nas áreas delimitadas em sua maioria não exigiam revisão ética e que havia pouca preocupação por parte do corpo docente e pouco conhecimento do corpo discente em esclarecer/entender a relevância de tal procedimento.

Palavras-chave: Pesquisa; Turismo; Hospitalidade; Lazer; Ética.

ABSTRACT - This paper has been the result of the interest in knowing if Brazilian graduated courses of tourism and of correlated areas have participated or at least have known the CEP/CONEP System (Comitê de Ética em Pesquisa/Comissão Nacional de Ética em Pesquisa - Committee of Ethics in Research/ National Commission of Ethics in Research). Here's the result. This paper has aimed to analyze the researches whose themes were tourism, hospitality and leisure and that were submitted to ethics analysis in order to organize researches with human beings with previous analysis by CEP/CONEP System using Plataforma Brasil. From the data, we have observed that the submitted research proposals on themes as tourism, hospitality and leisure are few in number and there were many recurrent subthemes in each one of the three chosen areas of analysis. Furthermore, it was possible to conclude that master and doctorate programs overwhelmingly did not require ethical review for human research, and there was little concern from the professors and little knowledge from the students in clarifying and understanding the relevance of this procedure.

Key words: Research; Tourism; Hospitality; Leisure; Ethics.

\footnotetext{
* Formação: Graduação em Turismo (Bacharelado) pela Universidade Federal de Juiz de Fora (UFJF); Especialização em Planejamento e Gestão Social (UFJF); Mestrado em Estudos Populacionais e Pesquisas Sociais pela Escola Nacional de Ciências Estatísticas vinculada ao Instituto Brasileiro de Geografia e Estatística (ENCE-IBGE). Doutorando em Geografia na Universidade de Brasília (UnB). Atividade profissional: Analista Técnico de Políticas Sociais no Ministério da Saúde. Endereço físico para correspondência: Esplanada dos Ministérios, Bloco G, CEP 70.058-900. Brasília - Distrito Federal (Brasil). Telefone: +55 61 3315-2683. E-mail: ricarduus@ gmail.com.
} 


\section{INTRODUÇÃO}

As pesquisas em turismo e hospitalidade vêm se desenvolvendo nos últimos anos com o aporte e contribuição de variadas orientações teórico-metodológicas. É inegável a contribuição que as perspectivas da pesquisa qualitativa trouxeram para a pesquisa em turismo, hospitalidade e lazer.

Um deslocamento nos objetos de estudos partindo-se de uma abordagem centralizada na renda - na qual as metodologias quantitativas davam conta de forma satisfatória - para uma abordagem com foco nas pessoas também tem ocorrido (COSTA; LIMA, 2014). Desta forma as pesquisas cuja abordagem inclui sensibilidade social e atenção às subjetividades envolvem pessoas como informantes e metodologias qualitativas cuja utilização não deve prescindir da preocupação ética.

Neste artigo consta uma revisão de literatura sobre ética (seção 2), sua interação com a ciência e o nascimento da bioética. Na seção 3, trazem-se algumas considerações sobre a ética em pesquisa nas ciências sociais e humanas. A seção 4 pontua as características do sistema brasileiro de revisão ética para pesquisas com seres humanos (Sistema CEP/CONEP).

No entanto, o ponto central deste trabalho são os dados apresentados nas seções 5 (material e método), 6 (resultados) e 7 (discussão) de uma pesquisa de natureza quantitativa sobre os protocolos de pesquisa com temas inseridos nas áreas de turismo, hospitalidade e lazer submetidos a análise ética no Sistema CEP/CONEP. A seção 8 traz as conclusões e a seção 9 as referências bibliográficas.

\section{REVISÃO DE LITERATURA}

Nesta seção se fez uma sucinta, no entanto essencial revisão de bibliografia sobre 1) ética, no que tange essencialmente à diferenciação entre ética deontológica e teleológica, e 2) ética e ciência, principalmente referências sobre o surgimento da bioética. 


\subsection{SOBRE ÉTICA}

O termo "ética" vem sendo desgastado pelo uso e apresenta múltiplos sentidos. O seu uso comum a confunde com moral, mas nem sempre ser 'moral' significa ser ‘ético'. Ética difere de moral no sentido de que a moral está relacionada aos costumes e usos de qualquer sociedade, servindo para se perceber o desejável e o indesejável; a ética traz uma reflexão crítica sobre a moral. Desta forma, certa moral vigente em dada sociedade pode estar a serviço da dominação, da opressão e, assim, pode ser questionada e considerada não ética. Da mesma forma, uma legislação poderá ser questionada quanto a sua moral e mais, quanto a sua validade ética.

FIGURA 1- ESQUEMA PARA ENTENDER AS INTERSECÇÕES ENTRE ÉTICA, MORAL E LEI

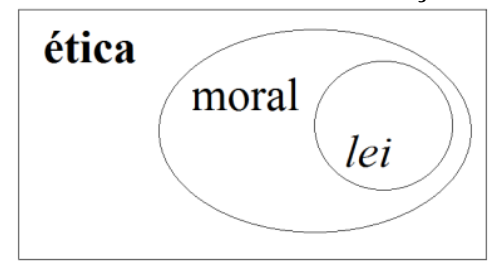

Fonte: elaboração própria, com base em GONTIJO (2013).

Cohen e Segre (2006) relacionam moral e ética com as funções mentais. Eles entendem que a moral estaria ligada a valores da vida em sociedade enquanto que a ética estaria ligada a valores individuais e sociais. Segundo os autores, a moral é uma função do superego e a ética é uma função do ego ou self. A moral lida exclusivamente com valores sociais, enquanto que a ética lida com valores individuais e sociais (COHEN; SEGRE, 2006, p. 18).

Há duas correntes no estudo da ética: a deontológica e a teleológica; estas correntes são definidas tal como segue:

- Deontológica ${ }^{1}$ : defendida por $\mathrm{Kant}^{2}$, nela se valoriza a intenção da ação (princípios que direcionam o comportamento) de acordo com o "dever", independente

\footnotetext{
${ }^{1}$ Deontologia significa "teoria do dever" ou "do que convém", em termos de ação; agir por dever e em função de uma boa intenção são os princípios que determinam a boa ação. Agir bem implica uma boa intenção e uma boa vontade. A ação é boa se a intenção (razão ou motivo) for boa e se ela for pensada como boa vontade, ou seja, se for universal (REDE SÃO PAULO DE FORMAÇÃO DOCENTE, 2011).

${ }^{2}$ Immanuel Kant (1724 - 1804) foi um filósofo alemão considerado figura central da filosofia moderna. O trecho citado por Gontijo está na obra: KANT, I. Fundamentação da Metafísica dos Costumes. Trad.: Antônio Pinto de Carvalho. Lisboa: Companhia Editora Nacional, 1964.
} 
das consequências (GONTIJO, 2013). O comportamento não deveria depender de circunstância; o principal seria o conceito de "dever" e depois o de resultado ou consequência; se um comportamento pode ser universalizado, então ele é ético (GONTIJO, 2013);

- Teleológica ${ }^{3}$ : defendida por autores como Aristóteles ${ }^{4}$, ela é uma ética consequencialista. Nela se entende o resultado como mais significativo que o "dever ser". A boa ação deve ser medida pelas consequências, ou seja, é a finalidade da ação é que deve determinar o modo de agir (GONTIJO, 2013).

Acerca dos códigos de ética profissionais (códigos deontológicos) Schramm (2004) afirma que, embora importantes para orientar moralmente o que o profissional deve fazer para ser considerado um agente respeitado eticamente, eles são insuficientes, porque deveriam ser considerados os possíveis efeitos dos atos, inclusive aqueles que podem ser daninhos e até nefastos, embora decorram das melhores intenções do agente moral.

Contemporaneamente, tem-se que a ética serve para analisar o contexto mundial como problema a fim de pensar a futura existência humana. São estudadas as mudanças éticas trazidas pelo impacto da tecnologia e da ciência e também a dominância da economia capitalista sobre as vidas das pessoas, em detrimento da política. Marilena Chauí (2000) descreve o principal constituinte da existência ética: o 'sujeito moral' ou 'sujeito ético' como um 'agente consciente', aquele que conhece a diferença entre bem/mal, certo/errado, permitido/proibido e virtude/vício.

Segundo Chauí (2000) para a existência do sujeito ético é preciso os seguintes requisitos: ser consciente de si e dos outros, refletir e reconhecer a existência dos outros como sujeitos éticos iguais a ele; ser dotado de vontade, ser capaz de controlar e orientar desejos, impulsos, tendências, sentimentos e decidir entre várias alternativas possíveis; ser responsável, reconhecer-se como autor da ação, avaliar os efeitos e consequências dela sobre si e sobre os outros; assumir a ação e suas consequências, responder por elas;

\footnotetext{
${ }^{3}$ Teleologia significa o "estudo do fim"; aliás, "teleos" significa fim, o fim da ação. Numa ação concreta, o mais importante não é saber se a intenção é boa, mas sim se teve boas consequências. Por isso se diz que é uma ética do concreto, que diria como se deve atingir a felicidade. Uma ação virtuosa é uma ação equilibrada que não peca por defeito nem por excesso. A ponderação da ação com vista ao fim que se deseja é a melhor das ações, sendo o meio-termo a melhor solução (REDE SÃO PAULO DE FORMAÇÃO DOCENTE, 2011).

${ }^{4}$ Aristóteles, pensador grego, desenvolveu um estudo sobre a ética centrada na razão prática para a realização humana plena: ARISTÓTELES. Ética à Nicômaco. São Paulo. Nova Cultural: 1996.
} 
ser livre, ser capaz de enxergar-se como origem de seus sentimentos, atitudes e ações, não estar submetido a poderes externos que o forcem e o constranjam a sentir, a querer e a fazer alguma coisa. A liberdade é o poder para autodeterminar-se, dando a si mesmo as regras de conduta.

\subsection{SOBRE ÉTICA E CIÊNCIA - BIOÉTICA}

Para Mori (2006, p. 20) a bioética, como conhecida, nasceu nos Estados Unidos entre o final da década de 1960 e o começo da década de 1970, quando diversos fatos histórico-culturais chamaram a atenção para a ética aplicada. A chamada "ética aplicada" incluiria, além da bioética, a ética dos negócios (business ethics) e a ética ambiental correspondendo a um novo interesse geral para a aplicação das "teorias éticas" a âmbitos específicos da vida social. Criticou-se este movimento de interesse por uma ética aplicada por ser, pelo menos quanto ao nome, redundante, pois a ética seria prática por natureza. (MORI, 2006, p. 20).

Mas, quais foram estes fatos que levantaram o debate sobre questões éticas práticas? Mori (2006) aponta que alguns escândalos relativos à experimentação clínica; o transplante de coração em 1967; os problemas levantados pela impossibilidade de generalizar a diálise; assim como questões mais gerais como aquelas relativas à desobediência civil dos jovens que deveriam ir à guerra do Vietnã e a questão do aborto, esta com papel central.

Segundo Mori (2006) foi Potter ${ }^{5}$ quem propôs um novo relacionamento entre o homem e a natureza. Para ele era urgente mudar a relação homem/natureza - até então baseada no instinto - levando a necessidade de uma "nova ciência" a partir da biologia que seria a bioética. Para Mori (2006) a bioética torna-se uma espécie de "ética científica" ou uma nova e geral "visão científica do mundo", que tem por objetivo garantir a sobrevivência humana e a qualidade da vida. Ten Have (2012) explica que nos Estados Unidos vigorou uma noção de bioética não como "ética científica", mas como a ética aplicada ao campo médico e biológico. Segundo Ten Have (2012), Potter ${ }^{6}$

\footnotetext{
${ }^{5}$ Oncologista Van Rensslaer Potter em sua obra POTTER, V. R. Bioethics. Bridge to the Future. Englewood Cliffs. New Jersey: Prentice-Hall Pub; 1971.

${ }^{6}$ POTTER, V. R. Bioethics. Bridge to the Future. Englewood Cliffs. New Jersey: Prentice-Hall Pub; 1971.
} 
se manifestou contra esta noção e, em novo esforço, cunhou o termo "bioética global" buscando ampliar o escopo da bioética para as questões em torno do meio ambiente e do futuro da humanidade (TEN HAVE, 2012, p. 43 e 59).

Emanuel (2006) afirma que durante os últimos 50 anos, as principais fontes de orientação ética sobre a realização de pesquisas clínicas têm sido o Código de Nurembergue $(1947)^{7}$, a Declaração de Helsinque $\left(1964^{8}\right.$ e versões posteriores), o Relatório Belmont $(1978)^{9}$ e as normas do CIOMS $(1993 ; 2003)^{10}$. O Código de Nurembergue, por exemplo, constituiu parte da decisão jurídica que condenou as atrocidades dos médicos nazistas (EMANUEL, 2006, p. 66).

Patrão Neves (2006) situa como conquista da sociedade, o aparecimento de várias declarações motivadas pelo propósito comum de proteção da pessoa em risco, incidindo primeiramente sobre as condições éticas da experimentação com seres humanos. A Declaração de Helsinque, da Associação Médica Mundial, veio a lume para preencher as lacunas percebidas no Código de Nurembergue, especialmente aquelas relacionadas com os médicos que realizavam pesquisas em pacientes (PATRÃONEVES, 2006). A Declaração de Helsinque sofreu alterações posteriores, sendo que a versão de Seul trouxe retrocesso ao flexibilizar o uso do placebo e descompromissar o patrocinador em relação aos participantes após o término da pesquisa (GARRAFA, 2012, p. 28).

Por sua vez, o Relatório Belmont foi elaborado para delimitar um marco filosófico e regulatório para responder aos escândalos de condutas antiéticas em pesquisas de saúde estadunidenses (Casos Tuskegee e Willowbrook). (EMANUEL, 2006, p. 66). Ainda, as normas do CIOMS/OMS foram concebidas para realizar a

\footnotetext{
${ }^{7}$ THE NUREMBERG CODE. Trials of War Criminals before the Nuremberg Military Tribunals under Control Council Law. n. 10, v. 2, p. 181-182. Washington: U. S. Government Printing Office, 1949.

8 WORLD MEDICAL ORGANIZATION. Declaration of Helsinki. British Medical Journal (7 December) 1996; 313 (7070): 1448-1449.

${ }^{9}$ UNITED STATES. The Belmont Report: ethical principles and guidelines for the protection of human subjects of research. [Bethesda, Md.]: The Commission, 1978.

${ }^{10}$ CIOMS é a sigla para Council for International Organizations of Medical Sciences dos EUA. A versão em língua portuguesa das diretrizes CIOMS foi publicada sob o seguinte título: CIOMS. Diretrizes Éticas Internacionais para a Pesquisa Biomédica em Seres Humanos. São Paulo: São Camilo; Loyola, 2004.
} 
aplicação da Declaração de Helsinque nos países "em vias de desenvolvimento" para ensaios em grande escala sobre vacinas e medicamentos (EMANUEL, 2006, p. 66).

A Declaração Universal sobre Bioética e Direitos Humanos, aclamada em 2005 pela Conferência Geral da Organização das Nações Unidas para a Educação, a Ciência e a Cultura (UNESCO) ${ }^{11}$, fixa princípios e procedimentos para orientar os Estados nacionais sobre a matéria de 'bioética' e reconhece a importância da liberdade de investigação científica e dos benefícios decorrentes dos progressos da ciência e da tecnologia (UNESCO, 2005). Nela se enfatiza também a necessidade de que essa investigação e os progressos dela oriundos se insiram no quadro dos princípios éticos enunciados e respeitem a dignidade humana, os direitos humanos e as liberdades fundamentais (UNESCO, 2005).

Entendia-se que o progresso da ciência e da tecnologia não poderia estar acima da dignidade humana, dos direitos humanos e das liberdades fundamentais. Enfim, conforme afirma Diniz (2008, p. 423), a aproximação de ética e pesquisa acadêmica deve ser realizada em torno de valores compartilhados universais tais como os direitos humanos, a proteção às populações vulneráveis e a promoção da ciência como um bem público.

\section{3 ÉTICA EM PESQUISA NAS CIÊNCIAS HUMANAS E SOCIAIS}

Atualmente, existe relativo consenso, nos países democráticos, de que toda pesquisa conduzida em qualquer área do conhecimento e que envolva seres humanos deva ser revisada em seus aspectos éticos e científicos (SCHRAMM, 2004). Deste ponto de vista, compartilhado socialmente, as ciências humanas e sociais também deveriam estar sujeitas a um sistema de revisão ética, ainda que as regras fossem menos criteriosas.

O campo destas ciências é abrangente e seus contornos são definidos por técnicas utilizadas e também pelo conhecimento produzido. A pesquisa social é definida como a em que se utilizam técnicas qualitativas para a coleta de dados (observação e observação participante, entrevistas, etnografia, grupo focal etc.) ou como a que adota

${ }^{11}$ UNESCO. Declaração Universal sobre Bioética e Direitos Humanos. Adotada por aclamação pela $33^{\text {a }}$ Sessão da Conferência Geral da UNESCO. Paris: UNESCO, 2005. 
procedimentos analíticos qualitativos (teoria fundamentada, análise de conteúdo, hermenêutica etc.) (DINIZ, 2008).

Nas humanidades em geral, inclusive no Brasil, houve resistência em reconhecer o aparato regulatório de revisão ética estabelecido, pois ele foi fundamentado em uma matriz disciplinar das ciências biomédicas (DINIZ, 2008, p. 418). O que levou os primeiros pesquisadores sociais a enfrentarem o tema da ética em pesquisa foi, em realidade, a imposição da revisão ética por meio das agências de fomento à pesquisa e das instituições de saúde onde haveria coleta de dados; mas também a exigência das revistas científicas que trabalhavam na interface entre biomedicina e humanidades (DINIZ; GUERRIERO, 2008).

Segundo Diniz (2008) cinco pesquisas são citadas como “clássicas" nos estudos de ética na pesquisa social com seres humanos por terem levantado questionamentos importantes. São elas:

- A pesquisa de W. F. Whyte ${ }^{12}$ sobre a vida social em um subúrbio dos EUA onde se levantaram questões sobre até onde o pesquisador deve inserir-se na vida social do pesquisado durante o trabalho de campo e quais os limites afetivos e éticos entre pesquisador e informante;

- A pesquisa sobre parentesco e genética entre os Yanomami de N. Chagnon ${ }^{13} \mathrm{e}$ Borofsky $^{14}$ onde se utilizou coleta de sangue dos índios e o incentivo a brigas e animosidade entre eles a fim de coletar dados sobre parentesco. Levantam-se questões não só sobre a forma de coleta de dados, mas também sobre como definir o compartilhamento de benefícios e ganhos financeiros da pesquisa;

- A pesquisa sobre práticas homossexuais em espaço público de L. Humphreys ${ }^{15}$ onde o pesquisador se utilizou de estratégias de dissimulação para aproximação dos informantes e disfarce a fim de buscar dados da vida familiar dos pesquisados. Levantou-se a questão de até onde pode avançar a curiosidade científica sobre a vida privada das pessoas;

\footnotetext{
${ }^{12}$ WHYTE, W. F. Revisiting Street Corner Society. Sociol. Forum. 1993; 8 (2): 285-98.

${ }^{13}$ CHAGNON, N. Yanomamö: the fierce people. New York: Holt, Rinehart and Winston; 1968.

${ }^{14}$ BOROFSKY, R. Yanomami: the fierce controversy and what we can learn from it. Berkeley: University of California Press; 2005.

${ }^{15}$ HUMPHREYS, L. Tearoom trade: impersonal sex in public places. New Brunswick: Aldine Transaction, 2008b. p. 223-232.
} 
- A pesquisa sobre aconselhamento genético na qual o pesquisador realizou etnografia sobre a atuação de uma equipe de saúde de C. Bosk ${ }^{16}$ onde apareceu a questão de como a etnografia pode se manter como método em consonância com as regras de revisão ética;

- A pesquisa sobre movimentos sociais de direitos dos animais de R. Scarce ${ }^{17}$ onde o pesquisador recusou-se a informar à polícia dados sobre ativistas que foram seus informantes sendo, por tal conduta, preso. Esta pesquisa trouxe à tona a questão de que não há garantia de sigilo e proteção da fonte para investigadores sociais como há para os jornalistas. Também colocou em debate a possibilidade de se pesquisar temas ilegais sem por em risco os participantes da pesquisa.

As particularidades metodológicas e éticas da pesquisa qualitativa foram pouco consideradas nos debates que deram origem aos sistemas de revisão ética de pesquisas com seres humanos e os dilemas para que estas ciências os reconheçam e participem deles não são fáceis (DINIZ; GUERRIERO, 2008, p. 79).

O debate requer atenção a aspectos como: 1) o estatuto epistemológico da produção do conhecimento nas humanidades envolve subjetividade e reciprocidade, 2) a forma de produção do conhecimento das ciências humanas e sociais envolve interação entre teoria e empiria, entre o pesquisador e o mundo social, 3) tem como característica não trabalhar com hipóteses, ou seja, não antecipar achados de pesquisa e 4) ao contrário da ética na pesquisa biomédica, que busca proteger os direitos do participante da pesquisa durante a fase de coleta de dados, a pesquisa social tem seus maiores problemas identificados nas fases de divulgação dos dados (DINIZ; GUERRIERO, 2008, p. 79-80).

Em suas particularidades, é necessário ser sensível ao fato de que os dilemas éticos das pesquisas sociais e de suas metodologias estão em como garantir anonimato e sigilo, ideias sobre representação justa, compartilhamento dos benefícios da pesquisa e devolução dos resultados.

\footnotetext{
${ }^{16}$ BOSK, C. L. All God's mistakes: genetic counseling in a pediatric hospital. Chicago: The University of Chicago Press; 1992. 192 p.

${ }^{17}$ SCARCE, R. (No) trial (but) tribulations: when courts and ethnography conflict. J Contemp Ethnog. 1994; 23 (2): p. 123-149.
} 


\section{A REVISÃO ÉTICA DE PESQUISAS COM SERES HUMANOS NO BRASIL - SISTEMA CEP/CONEP}

No Brasil o sistema de revisão ética foi criado pela Resolução $n^{\circ} 196 / 96^{18}$ do Conselho Nacional de Saúde (CNS) que instituiu a Comissão Nacional de Ética em Pesquisa (CONEP) como uma instância colegiada, de natureza consultiva, educativa e formuladora de diretrizes e estratégias (BRASIL, 1996). Sua principal atribuição é o exame dos aspectos éticos das pesquisas que envolvem seres humanos e sua missão é elaborar e atualizar as diretrizes e normas para a proteção dos sujeitos de pesquisa (no processo de coleta de dados, mais especificamente). Também coordena a rede de Comitês de Ética em Pesquisa das instituições locais (BRASIL, 1996).

A história de criação da CONEP, vinculada ao CNS e Ministério da Saúde evidencia sua ligação forte com a pesquisa relacionada às ciências biomédicas e com a proteção dos usuários do Sistema Único de Saúde (SUS) enquanto participantes das variadas pesquisas (BRASIL, 2006).

No sistema se utiliza, como meio de realizar suas atribuições, uma plataforma online para submissão, avaliação e liberação de pareceres. Trata-se da Plataforma Brasil, disponível no endereço eletrônico: <http://aplicacao.saude.gov.br/plataformabrasil/ login.jsf> (BRASIL, 2006).

Segundo Diniz (2007), com a consolidação do Sistema CEP/CONEP nas universidades e centros de pesquisa consolidaram-se também as críticas à "insensibilidade" do sistema às metodologias e técnicas da pesquisa social. Conforme expõe a autora, muitos pesquisadores sociais relatam as dificuldades que experimentam ao submeter seus protocolos ao Sistema. O Sistema foi elaborado tendo como referência os campos biomédicos e suas particularidades metodológicas, muito embora na Resolução CNS no 196/96 se tenha pretensões de que todos os campos disciplinares submetam seus projetos de pesquisa aos comitês (DINIZ, 2007, p. 286-287).

\footnotetext{
${ }^{18}$ CONSELHO NACIONAL DE SAÚDE. Resolução $\mathrm{n}^{\circ} 196$ de 10 de outubro de 1996. Aprova as diretrizes e normas regulamentadoras de pesquisas envolvendo seres humanos. Comissão Nacional de Ética em Pesquisa, Brasília, DF.
} 
Atualmente, a Resolução CNS n 466/12 ${ }^{19}$ substituiu a Resolução nº 196/96 e estabelece em seu item XIII.3 que "as especificidades éticas das pesquisas nas ciências sociais e humanas e de outras que se utilizam de metodologias próprias dessas áreas serão contempladas em resolução complementar, dadas suas particularidades" (CONSELHO NACIONAL DE SAÚDE, 2012, Item XIII.3). Conforme Carta Circular da CONEP foi criada no âmbito daquela Comissão um grupo de trabalho para criação desta resolução específica para as ciências humanas e sociais, no entanto, ainda sem resultados divulgados (COMISSÃO NACIONAL DE ÉTICA EM PESQUISA, 2014).

\section{MATERIAL E MÉTODO}

As análises deste artigo foram realizadas a partir de dados extraídos da Plataforma Brasil (PlatBr) desde o ano de 2009 quando foi criada a PlatBr até o mês de janeiro de 2014, quando as consultas foram realizadas. Foram buscados na $\mathrm{PlatBr}$ os protocolos que continham em seu título uma série de palavras-chave relacionadas a temas de pesquisa comuns a cada área. Foram utilizadas as seguintes palavras-chave:

\begin{tabular}{|c|c|c|}
\hline QUADRO 1 - TEMAS DE PESQUISA E RESPECTIVAS PALAVRAS-CHAVE. \\
\hline TURISMO & HOSPITALIDADE $^{20}$ & LAZER \\
\hline turismo / turista & hospitalidade & lazer \\
\hline viagem / viajante & hotel / hotelaria & recreação \\
\hline turístico / turística & receptivo & entretenimento \\
\hline visitação & & diversão \\
\hline
\end{tabular}

Obs.: elaboração própria com dados da Plataforma Brasil 2004.

Os resultados das buscas foram analisados a fim de retirar os que pudessem ter sido apresentados de forma errônea pelo sistema e que não eram adequadas à finalidade da pesquisa (p. ex: no caso da busca com a palavra 'turismo', o sistema retornava protocolos com a palavra 'fisiculturismo'). A seguir, os resultados foram consolidados

${ }^{19}$ CONSELHO NACIONAL DE SAÚDE. Resolução no 466 de 12 de dezembro de 2012. Aprova diretrizes e normas regulamentadoras de pesquisas envolvendo seres humanos Comissão Nacional de Ética em Pesquisa, Brasília, DF.

${ }^{20}$ O termo 'hospitalidade' aqui foi utilizado no sentido mais específico de 'hospitalidade comercial' já que na busca realizada na Plataforma Brasil foram utilizadas as palavras-chave como hotel, hotelaria e receptivo. 
em uma só lista, foram identificados e retirados protocolos duplicados. Identificaram-se 244 protocolos de pesquisa arrolados no sistema de análise ética da Comissão Nacional de Ética em Pesquisa (CONEP). Eles representavam apenas 0,05\% do total dos protocolos de pesquisa, que até janeiro de 2014, já passavam de 4.853 submetidos por meio da Plataforma Brasil ${ }^{21}$.

Cabe ainda registrar que foram tentadas buscas com outras palavras-chave, como por exemplo, turismólogo, tour, guia de turismo, entretenimento e turistificação na PlatBr, mas no entanto, não retornaram nenhum item.

Não foi o objetivo deste trabalho, levantar todos os protocolos relativos às 3 áreas citadas, visto não ser possível buscar todas as palavras-chave utilizadas nos trabalhos acadêmicos da área. Em vista disso, considera-se pertinente ressaltar que os 244 protocolos cadastrados foram uma amostra significativa dos projetos de pesquisa das áreas de turismo, hospitalidade e lazer cadastrados na PlatBr. Com esta ressalva, foi possível fazer algumas análises e propor algumas conclusões acerca dos protocolos de pesquisa levantados. Estes protocolos foram analisados quantitativamente embora tenha sido possível também realizar algumas considerações de cunho qualitativo. Os resultados são os apresentados a seguir.

\section{RESULTADOS}

Foram levantados 244 protocolos cadastrados na PlaBr, os quais estavam distribuídos da seguinte maneira: 30\% com palavras chave da área de turismo, 16\% com palavras-chave da área de hospitalidade e 54\% com palavras-chave da área de lazer. $\mathrm{Na}$ tabela abaixo se sintetizam as informações.

TABELA 1 - PROTOCOLOS DE PESQUISA/ÁREAS TEMÁTICAS

\begin{tabular}{c|c|c|c}
\hline ÁREA & 1 - TURISMO & 2 - HOSPITALIDADE & 3 - LAZER \\
\hline $\begin{array}{c}\text { Palavras- } \\
\text { chave }\end{array}$ & $\begin{array}{c}\text { turismo, turista, viagem, } \\
\text { viajante, turístico, } \\
\text { turística, visitação }\end{array}$ & $\begin{array}{c}\text { hospitalidade, hotel, } \\
\text { hotelaria, receptivo }\end{array}$ & $\begin{array}{c}\text { lazer, recreação, } \\
\text { entretenimento, diversão }\end{array}$ \\
\hline $\mathrm{n}^{\mathrm{o}}$ & 72 & 40 & 131 \\
\hline$\%$ & $30 \%$ & $16 \%$ & $54 \%$ \\
\hline
\end{tabular}

Fonte: elaboração própria com dados da Plataforma Brasil, 2014.

${ }^{21}$ Fonte: indicadores de utilização da Plataforma Brasil apresentados na tela inicial ao se fazer login. 
Destes dados pôde-se observar que os protocolos que abordavam a temática do lazer corresponderam a mais da metade $(54 \%)$ dos protocolos levantados seguida pela temática do turismo (30\%) e pela temática da hospitalidade (16\%). Ao tentar identificar o porquê desta discrepância, buscou-se levantar também as instituições que tinham maior número de protocolos submetidos conseguindo-se identificar que a Universidade Federal de Minas Gerais (UFMG) tinha relevância na análise.

Em pesquisa à página eletrônica do Programa de Pós-Graduação Interdisciplinar em Estudos do Lazer da UFMG conseguiu-se descobrir que em seu regulamento havia a exigência de encaminhar projeto de dissertação ou tese ao Comitê de Ética da UFMG ${ }^{22}$.

Em seguida, voltou-se para os temas mais específicos inseridos dentro das 3 áreas temáticas principais escolhidas. Para esta análise o pesquisador observou cada título do protocolo de pesquisa e foi identificado um subtema específico que poderia resumir a temática abordada em cada pesquisa. Os dados revelaram que alguns subtemas continham mais protocolos submetidos, ou seja, supostamente mais atentos à questão ética do que outros. Ver tabelas 2,3 e 4.

TABELA 2 - ÁREA 1 - TURISMO

\begin{tabular}{l|c|c}
\hline TEMA PRINCIPAL OBSERVADO NO TÍTULO & $\mathrm{n}^{\circ}$ & $\%$ \\
\hline Comunidade / turismo de base comunitária / turismo de base local & 19 & $26 \%$ \\
\hline Ecoturismo / desenvolvimento sustentável / sustentabilidade & 10 & $14 \%$ \\
\hline Saúde do turista / turismo de saúde & 9 & $13 \%$ \\
\hline Educação / aprendizagem & 5 & $7 \%$ \\
\hline Eventos & 5 & $7 \%$ \\
\hline Potencialidades do desenvolvimento turístico / atrativos & 4 & $6 \%$ \\
\hline Profissional & 3 & $4 \%$ \\
\hline Gastronomia & 2 & $3 \%$ \\
\hline Roteiro & 2 & $3 \%$ \\
\hline Turismo religioso & 2 & $3 \%$ \\
\hline Ferramentas da web aplicadas às áreas & 2 & $3 \%$ \\
\hline Outros ${ }^{23}$ & 9 & $13 \%$ \\
\hline Total & 72 & $100 \%$ \\
\hline Fonte: elaboraça proppia com dados da Platforma Brasil
\end{tabular}

Fonte: elaboração própria com dados da Plataforma Brasil, 2014.

\footnotetext{
${ }^{22}$ O Regulamento citado define em seu Art. 47 que “Após homologação do Colegiado, o projeto deverá ser registrado e aprovado pelo Departamento ou órgão equivalente do professor orientador e será encaminhado ao Comitê de Ética em Pesquisa - COEP da UFMG, quando couber, acompanhado dos respectivos Pareceres" (UNIVERSIDADE FEDERAL DE MINAS GERAIS, s/d).

${ }^{23}$ Outros subtemas observados (cada 1 subtema com 1 observação): acessibilidade, atrativos, finanças, identidade cultural, jornalismo, migração, políticas públicas, promoção e turismo geocientífico.
} 
$\mathrm{Na}$ área temática 1 (turismo) observou-se que grande parte dos protocolos submetidos trabalhava com temáticas relacionadas à relação do turismo com as comunidades receptoras, ao turismo de base local ou ao turismo de base comunitária (26\%) e ao ecoturismo ou desenvolvimento sustentável (14\%).

TABELA 3 - ÁREA 2 - HOSPITALIDADE

\begin{tabular}{c|c|c}
\hline TEMA PRINCIPAL OBSERVADO NO TÍTULO & $\mathrm{n}^{\circ}$ & $\%$ \\
\hline Hotelaria hospitalar & 7 & $18 \%$ \\
\hline Saúde do trabalhador da hospitalidade & 6 & $15 \%$ \\
\hline Gestão de pessoas na hospitalidade (hotelaria) & 4 & $10 \%$ \\
\hline Alimentos e bebidas na hospitalidade (hotelaria) & 4 & $10 \%$ \\
\hline Hotelaria $^{\text {Hóspede/consumidor/paciente de hospital }}$ & 2 & $5 \%$ \\
\hline Outros $^{24}$ & 3 & $8 \%$ \\
\hline Total $^{2}$ & 14 & $35 \%$ \\
\hline
\end{tabular}

Fonte: elaboração própria com dados da Plataforma Brasil, 2014.

$\mathrm{Na}$ área temática 2 (hospitalidade) observou-se que os protocolos abordavam mais temas mais próximos à saúde, tais como aqueles relacionados com a hotelaria hospitalar e à saúde do trabalhador da hospitalidade (tanto em hotéis como hospitais). Ainda que tivessem como tema a hospitalidade, várias destas pesquisas não tinham como origem cursos das áreas de turismo, lazer ou hospitalidade, mas sim os próprios cursos da área de saúde.

\begin{tabular}{|c|c|c|}
\hline $\begin{array}{l}\text { TEMA PRINCIPAL OBSERVADO NO } \\
\text { TÍTULO }\end{array}$ & $\mathrm{n}^{\mathrm{o}}$ & $\%$ \\
\hline Lazer de públicos específicos ${ }^{25}$ & 35 & $27 \%$ \\
\hline Idosos/terceira idade/envelhecimento & 20 & $15 \%$ \\
\hline Educação/formação & 14 & $11 \%$ \\
\hline Recreação & 12 & $9 \%$ \\
\hline
\end{tabular}

\footnotetext{
24 Outros subtemas observados (cada 1 subtema com 1 observação): recepção, qualidade, publicidade/propaganda, lazer em hotel, imigração, idosos, hospital, higiene, gestão estratégica, gastronomia, educação, custos, atendimento e acolhimento.

${ }^{25}$ Lazer de professores universitários, de profissionais de enfermagem, de mulheres, de pacientes de CAPs, de praticantes de stand up paddle, de jovens trabalhadores, de homens, de consumidores, de crianças, de adultos, de atletas, de brasileiros, de estudantes, de pessoas com necessidades especiais, de professores de educação física, de trabalhadores/funcionários, de adolescentes, de gestantes, da juventude, de portadores de doenças.
} 
Continuação...

\begin{tabular}{l|c|c}
\hline Outros & 11 & $8 \%$ \\
\hline Profissional do lazer & 10 & $8 \%$ \\
\hline Espaços/Equipamentos de lazer & 8 & $6 \%$ \\
\hline Políticas públicas de lazer/esporte & 6 & $5 \%$ \\
\hline Lazer de comunidades & 4 & $3 \%$ \\
\hline Esporte & 4 & $3 \%$ \\
\hline Lazer e turismo & 3 & $2 \%$ \\
\hline Diversão & 2 & $2 \%$ \\
\hline Lazer e saúde & 2 & $2 \%$ \\
\hline Total & 131 & $100 \%$ \\
\hline
\end{tabular}

Fonte: elaboração própria com dados da Plataforma Brasil, 2014.

$\mathrm{Na}$ área temática 3 (lazer) - área que teve maior número de protocolos de pesquisa identificados na $\mathrm{PlatBr}$-, os temas mais frequentes além daqueles relacionados a públicos específicos $(27 \%)$ foram os relacionados à terceira idade e ao envelhecimento (15\%), à formação e educação (11\%), à recreação $(9 \%)$ e aos profissionais do lazer $(8 \%)$.

Com esta visão geral dos temas mais recorrentes em cada área, também foi examinado quais eram as instituições que mais submeteram protocolos de pesquisa ao sistema. Na tabela a seguir mostra-se o resultado encontrado:

TABELA 5 - INSTITUIÇÕES / QUANTIDADE DE PROTOCOLOS SUBMETIDOS.

\begin{tabular}{l|c}
\hline INSTITUIÇÃO & $\begin{array}{c}\text { N }^{\circ} \text { DE } \\
\text { PROTOCOLOS }\end{array}$ \\
\hline Universidade Federal de Minas Gerais - UFMG & 19 \\
\hline Universidade Federal do Amazonas - UFAM & 9 \\
\hline Universidade Estadual de Maringá - UEM & 8 \\
\hline Universidade Estadual do Oeste do Paraná - UNIOESTE & 7 \\
\hline Associação Paranaense de Cultura - PUC-PR & 6 \\
\hline Centro de Estudos Superiores de Maceió - CESMAC & 6 \\
\hline Faculdade de Ciências Medicas - UNICAMP & 6 \\
\hline Universidade Federal da Paraíba - Centro de Ciências da Saúde & 6 \\
\hline Outras instituições - com de 1 a 5 protocolos cada & 177 \\
\hline Total & 244 \\
\hline
\end{tabular}

Fonte: elaboração própria com dados da Plataforma Brasil, 2014 
Desta forma, observou-se que a UFMG foi a instituição que mais enviou protocolos de pesquisa das áreas turismo, hospitalidade e lazer para revisão ética pelo Sistema CEP/CONEP.

\section{DISCUSSÃO}

A primeira questão que foi trabalhada referiu-se à existência de comitês de ética em pesquisa nas universidades mantenedoras de programas de pós-graduação nas áreas de estudo selecionadas. Foi pesquisada junto às coordenações ou secretarias de tais programas (via telefone ou correio eletrônico) a existência de exigência regimental nos programas de pós-graduação em Turismo, Hospitalidade e Lazer.

Descobriu-se que somente o Programa de Pós-Graduação em Estudos do Lazer da UFMG dispunha objetivamente - art. 47 - sobre a obrigação de submissão a revisão ética os projetos de pesquisa com seres humanos (UNIVERSIDADE FEDERAL DE MINAS GERAIS, s./d., p. 7). Isto se dá a despeito do fato de que todas as instituições pesquisadas que estavam ofertando os programas de pós-graduação nas áreas mantinham comitês de ética em pesquisa.

TABELA 6 - EXISTÊNCIA DE COMITÊ DE ÉTICA E EXIGÊNCIA DE REVISÃO ÉTICA NOS PROGRAMAS DE PÓS-GRADUAÇÃO EM TURISMO, HOSPITALIDADE E LAZER

\begin{tabular}{|c|c|c|c|c|}
\hline PROGRAMA & IES & $\begin{array}{l}\text { NOTA } \\
\text { CAPES }\end{array}$ & $\begin{array}{l}\text { COMITÊ DE } \\
\text { ÉTICA }\end{array}$ & \begin{tabular}{|c} 
EXIGÊNCIA DE \\
REVISÃO \\
ÉTICA \\
\end{tabular} \\
\hline \multicolumn{5}{|c|}{ Cursos de Doutorado e Mestrado } \\
\hline Turismo e Hotelaria & Univali & 5 & Há & Não há \\
\hline Estudos do Lazer & UFMG & 4 & Há & Há \\
\hline \multicolumn{5}{|c|}{ Cursos de Mestrado } \\
\hline Hospitalidade & UAM & 3 & Há & $*$ \\
\hline Turismo & UFPR & 3 & Há & Não há. \\
\hline Turismo & UFRN & 3 & Há & Não há. \\
\hline Turismo & UCS & 3 & Há & Não há. \\
\hline \multicolumn{5}{|c|}{ Cursos de mestrado profissional } \\
\hline Gestão de Negócios Turísticos & UECE & 3 & Há & $*$ \\
\hline Turismo & $\mathrm{UnB}$ & 3 & Há & Não há. \\
\hline
\end{tabular}

*A informação não estava disponível na internet nem foi fornecida pela Coordenação.

Fonte: Elaboração própria com dados da SNPG/CAPES acessados em 17/01/2014. 
Cabe a ressalva de que o Programa de Pós-Graduação da Universidade do Vale do Itajaí (Univali) embora não tivesse nenhum tipo de exigência regimental quanto à submissão ao sistema de revisão ética, colocava - em seu artigo 46 inciso III - como atribuição dos orientadores o enquadramento a "preceitos éticos" do curso: "acompanhar e orientar a pesquisa de Dissertação/Tese, submetendo-se aos preceitos éticos metodológicos e científicos estabelecidos pelo Curso e/ou Programa, bem como efetuar a indicação da bibliografia básica” (UNIVERSIDADE DO VALE DO ITAJAÍ, 2009, p. 15).

A preocupação com o tema por parte das instituições de pesquisa na área com o tema é, sem dúvidas, uma demonstração de que ética vem tomando espaço nas áreas de turismo, lazer e hospitalidade. A ANPTUR (Associação Nacional de Pesquisa e PósGraduação em Turismo) discutiu em seu congresso anual de 2010 o tema da ética e a produção e difusão da pesquisa em turismo. Os membros da ANPTUR avançaram na discussão do tema tendo ocorrido duas mesas redondas sobre as questões éticas na produção e difusão do conhecimento e uma oficina abordando dilemas e problemas éticos nas pesquisas científicas em turismo.

Trabalhos científicos sobre ética nas áreas de turismo, lazer e hospitalidade são escassos, mas não inéditos. Melo (2012) realizou pesquisa no âmbito do Programa de Pós-Graduação em Turismo da Universidade Federal do Rio Grande do Norte acerca da preocupação ética dos estudantes de 3 cursos de pós-graduação na área de turismo de diferentes universidades. A pesquisadora demonstrou que: 1) O principal desafio ético encontrado pelos alunos de pós-graduação estava no relacionamento com o sujeito da pesquisa, que acontece na fase de coleta de dados; 2) Nenhum dos estudantes entrevistados para a pesquisa enviou qualquer projeto para ser avaliado por um Comitê de Ética em Pesquisa (CEP); 3) A maioria dos estudantes que participaram da pesquisa não conhecia a resolução e demais normas sobre ética em pesquisa com seres humanos em nível nacional.

A primeira conclusão de Melo (2012), baseada na opinião dos estudantes entrevistados, foi em sentido contrário ao afirmado por Diniz e Guerriero (2008). Neste caso, as autoras afirmaram que os maiores problemas identificados nas pesquisas sociais se localizavam nas fases de divulgação e não na coleta de dados como concluiu Melo (2012) com base na pesquisa que fez com os alunos de pós-graduação em turismo. 
Melo (2012) concluiu que os discentes de pós-graduação em turismo pesquisados possuíam pouco conhecimento quanto às normas e orientações sobre ética em pesquisa e demonstraram desconhecer os benefícios que a ética em pesquisa traz com relação à proteção e preservação do participante, bem como quanto aos benefícios que gera a sociedade como um todo.

Pode-se inferir que se os estudantes demonstraram ter pouco conhecimento sobre ética em pesquisa, uma parte da responsabilidade se encontrava com os próprios departamentos e programas de graduação e pós-graduação que não exigiam de seus alunos a revisão ética dos projetos de pesquisa e poderiam não estar fazendo o uso dos Comitês de Ética de suas próprias instituições. Da mesma forma, os Comitês de Ética em Pesquisa - CEP das instituições deveriam realizar a sensibilização dos alunos e professores sobre a importância da revisão ética nas pesquisas que envolvam seres humanos.

\section{CONCLUSÃO}

Os gestores dos cursos de turismo, hospitalidade e lazer - seja em nível de graduação ou pós-graduação - precisam travar debate mais aprofundado sobre a revisão ética dos projetos de pesquisa que envolvam seres humanos, inclusive entrando no movimento de flexibilização das normas do Sistema em função das características das ciências humanas e sociais. Conforme levantado, os cursos da UFMG e Univali caminhavam neste sentido de ampliar este debate devendo se orientar pelo esforço de transformação do sistema brasileiro de revisão ética (Sistema CEP/CONEP) a fim de contemplar as especificidades do saber das ciências humanas, da pesquisa social e das metodologias de orientação qualitativa.

Não é preciso mencionar que os dilemas das pesquisas sociais também dizem respeito às pesquisas em turismo, hospitalidade e lazer. São questões como as seguintes, que foram levantadas em casos conhecidos por problemas éticos: até onde o pesquisador deve se inserir na vida social do pesquisado durante o trabalho de campo? Quais os limites afetivos e éticos entre pesquisador e informante? Quais os cuidados para que o pesquisador não dê origem a conflitos e animosidade nos contextos onde atuem a fim de 
coletar dados? Como definir o compartilhamento de benefícios por ventura gerados pelas pesquisas e eventuais ganhos financeiros decorrentes dela? Manifesta-se a preocupação em, pelo menos, comunicar os resultados encontrados aos informantes ou participantes da pesquisa? Até onde pode avançar a curiosidade científica dos pesquisadores sobre a vida privada das pessoas? Como fazer uso da etnografia - método antropológico também utilizado nas pesquisas de turismo, hospitalidade e lazer - em consonância com as regras de revisão ética?

A tarefa proposta abrange uma mudança cultural e não será fácil de ser cumprida. Até a data da pesquisa na Plataforma, os protocolos de pesquisa em turismo, hospitalidade e lazer (244) eram uma parcela muito pequena $(0,05 \%)$ no âmbito dos protocolos submetidos a revisão ética por meio da Plataforma Brasil. O desafio compreende não somente aumentar este número, mas incrementar e qualificar o debate sobre o tema.

Dos dados apresentados, pôde-se perceber também que no âmbito das 3 áreas estudadas haviam temas que pareceram se sobressair mais que outros. No caso da área temática do turismo sobressaíram-se as pesquisas cujos temas envolvessem comunidade, turismo de base comunitária, turismo de base local, ecoturismo, desenvolvimento sustentável e sustentabilidade. Na área temática de hospitalidade sobressaiu-se o tema da hotelaria hospitalar, o da saúde do trabalhador, o da gestão de pessoas e o dos alimentos e bebidas. A hotelaria hospitalar apareceu encabeçando a lista pelo fato de as pesquisas em hospitais terem maior controle e maior exigência de passarem por revisão ética. $\mathrm{Na}$ área do lazer, as preocupações éticas se voltaram mais para pesquisas em que se buscaram investigar o lazer de estratos sociais como jovens, mulheres, profissionais específicos etc. Também se sobressaíram as pesquisas sobre o lazer de idosos ou que abordaram o lazer e o envelhecimento.

Pode-se dizer que estes são temas cuja preocupação acadêmica central perpassa o ser humano, sua convivência com o ambiente e a preocupação com o futuro das gerações vindouras. Não por acaso, são - no âmbito dos estudos do turismo, lazer e hospitalidade -, os que mais se aproximam do conceito de bioética em sua acepção original, dada por $\operatorname{Potter}^{26}$. No conceito original do termo "bioética", depois enfatizado

\footnotetext{
${ }^{26}$ POTTER, V. R. Bioethics. Bridge to the Future. Englewood Cliffs. New Jersey: Prentice-Hall Pub; 1971.
} 
no conceito de "bioética global", se busca ampliar o escopo da bioética para as questões em torno do meio ambiente e do futuro da humanidade.

Este artigo é uma contribuição muito singular para o debate científico da ética em relação às pesquisas em turismo, lazer e hospitalidade. Futuras pesquisas podem se debruçar sobre o conteúdo e metodologias dos protocolos submetidos e podem também buscar investigar, com mais profundidade e com metodologia qualitativa, como os cursos tratam do tema.

\section{REFERÊNCIAS}

BRASIL. Ministério da Saúde, Secretaria de Ciência, Tecnologia e Insumos Estratégicos, Departamento de Ciência e Tecnologia. Capacitação para Comitês de Ética em Pesquisa - CEPs, v. 1. Brasília: Ministério da Saúde, 2006.

Normas regulamentadoras sobre pesquisa em seres humanos. Brasília: Conselho Nacional de Saúde, Ministério da Saúde; 1996.

CHAUÍ, M. Convite à Filosofia. São Paulo: Editora Ática, 2000.

COHEN, C.; SEGRE, M. Texto 1 - Breve discurso sobre calores, moral, eticidade e ética. In: BRASIL. Ministério da Saúde, Secretaria de Ciência, Tecnologia e Insumos Estratégicos, Departamento de Ciência e Tecnologia. Capacitação para Comitês de Ética em Pesquisa - CEPs, v. 1. Brasília: Ministério da Saúde, 2006. p. 14-19.

COMISSÃO NACIONAL DE ÉTICA EM PESQUISA. Carta Circular $\mathbf{n}^{\circ} \mathbf{1 0 0 / 2 0 1 4}$ Texto informativo sobre GT - Pesquisas em Ciências Sociais e Humanas. Brasília, 2014. Disponível em <http://conselho.saude.gov.br/web_comissoes/conep/aquivos/ CartaCircular100-2014.pdf>. Acesso em: 27/01/2014.

CONSELHO NACIONAL DE SAÚDE. Resolução no 466 de 12 de dezembro de 2012. Aprova diretrizes e normas regulamentadoras de pesquisas envolvendo seres humanos Comissão Nacional de Ética em Pesquisa, Brasília, 2012.

Resolução no 196 de 10 de outubro de 1996. Aprova as diretrizes e normas regulamentadoras de pesquisas envolvendo seres humanos. Comissão Nacional de Ética em Pesquisa, Brasília, 1996.

COSTA, J. B. A da; LIMA, R. M. M de. Os caminhos do desenvolvimento no turismo: o deslocamento da abordagem centralizada na renda para a abordagem com foco nas pessoas. Turismo \& Sociedade. Curitiba, v. 7, n. 2, p. 201-227, abril de 2014. 
DINIZ, D. Ética na pesquisa em ciências humanas: novos desafios. Ciência \& Saúde Coletiva, Rio de Janeiro, v. 13, n. 2, p. 417-426, mar./abr. 2008. Disponível em: $<$ http://www.scielosp.org/pdf/csc/v13n2/a17v13n2.pdf>. Acesso em: 05/11/2013.

Avaliação ética em pesquisa social: o caso do sangue Yanomami. Revista Bioética 2007, v. 15, n. 2, p. 284-297. Disponível em <http://repositorio.unb.br/ bitstream/10482/8202/1/ARTIGO_AvaliacaoEticaPesquisaSocial.pdf $>$. Acesso em: $14 / 01 / 2014$.

; GUERRIERO, I. C. Z. Ética na pesquisa social: desafios ao modelo biomédico. RECIIS - R. Eletrônica de Comunicação, Informação \& Inovação em Saúde. Rio de Janeiro, v. 2, Sup.1, p. Sup.78-Sup. 90, dez., 2008.

EMANUEL, E. Texto 8 - O que faz que a pesquisa clínica seja considerada ética? Sete requisitos éticos fundamentais. In: BRASIL. Ministério da Saúde, Secretaria de Ciência, Tecnologia e Insumos Estratégicos, Departamento de Ciência e Tecnologia. Capacitação para Comitês de Ética em Pesquisa - CEPs, v. 1. Brasília: Ministério da Saúde, 2006. p. 66-75.

GARRAFA, V. O Congresso Mundial de 2002, a Declaração da UNESCO de 2005 e a ampliação e politização da agenda bioética internacional no século XXI. In: PORTO, D.; GARRAFA, V.; MARTINS, G. Z.; BARBOSA, S. N. (Orgs.). Bioéticas, Poderes e Injustiças: 10 anos depois. Brasília: CFM/Cátedra Unesco de Bioética/SBB, 2012, p. 43-61.

GONTIJO, P. Ética e serviço público. Brasília: ENAP (Curso de Ambientação para Analista Técnico de Políticas Sociais), 2013. 29 slides: color; Disponível em: <http://repositorio.enap.gov.br/>. Acesso em: 26/01/2014.

MELO, F. L. S. Ética na pesquisa em turismo: percepções de discentes de programas de pós-graduação stricto sensu em turismo - UFRN, UCS e UNIVALI. 2012. 109 p. Dissertação (Mestrado) Programa de Pós-Graduação em Turismo - Universidade Federal do Rio Grande do Norte. Natal. 2012.

MORI, M. Texto 2 - A bioética: sua natureza e história. (Trad. Fermin Roland Schramn). In: BRASIL. Ministério da Saúde, Secretaria de Ciência, Tecnologia e Insumos Estratégicos, Departamento de Ciência e Tecnologia. Capacitação para Comitês de Ética em Pesquisa - CEPs, v. 1. Brasília: Ministério da Saúde, 2006. p. 20-28.

NASSAR, Z. A. Ética e turismo. Turismo. Visão e Ação, ano IV, n. 8, p. 67-82, abr./set. 2001. Disponível em <http://www6.univali.br/seer/index.php/rtva/ article/view/1272/986>. Acesso em: 05/11/2013.

PATRÃO-NEVES, M. C. Texto 3 - A bioética e sua evolução. In: BRASIL. Ministério da Saúde, Secretaria de Ciência, Tecnologia e Insumos Estratégicos, Departamento de Ciência e Tecnologia. Capacitação para Comitês de Ética em Pesquisa - CEPs, v. 1. Brasília: Ministério da Saúde, 2006. p. 29-41. 
REDE SÃO PAULO DE FORMAÇÃO DOCENTE. Ética. São Paulo: UNESP; REDEFOR, 2011. Disponível em: <http://www.acervodigital.unesp.br/bitstream/ 123456789/40555/4/2ed_filo_m2d3.pdf>. Acesso em: 01/11/2013.

SCHRAMM, F. R. A moralidade da prática de pesquisa nas ciências sociais: aspectos epistemológicos e bioéticos. Ciência \& Saúde Coletiva [online]. 2004, v. 9, n. 3, p. 773-784. Disponível em: <http://dx.doi.org/10.1590/S1413-81232004000300028>. Acesso em: 06/02/2014.

TEN HAVE, H. A. M. J. Bioética sem fronteiras. In: PORTO, D.; GARRAFA, V.; MARTINS, G. Z.; BARBOSA, S. N. (Orgs.). Bioéticas, Poderes e Injustiças: 10 anos depois. Brasília: CFM/Cátedra Unesco de Bioética/SBB, 2012, p. 43-61.

UNESCO. Declaração Universal sobre Bioética e Direitos Humanos. Adotada por aclamação em 19 out. 2005, 33 ${ }^{\mathrm{a}}$ sessão da Conferência Geral. Disponível em $<$ http://unesdoc.unesco.org/images/0014/001461/146180por.pdf〉. Acesso em: $16 / 11 / 2013$.

UNIVERSIDADE DO VALE DO ITAJAÍ. Regimento dos Programas Acadêmicos de Pós-graduação Stricto Sensu - Anexo da resolução n. ${ }^{0}$ 093/CONSUNCaPPEC/09. Itajaí: UNIVALI, 2009. Disponível em <http://www.univali.br/ensino/ pos-graduacao/mestrado/>. Acesso em: 27/01/2014.

UNIVERSIDADE FEDERAL DE MINAS GERAIS. Regulamento Programa de Pósgraduação Interdisciplinar em Estudos do Lazer. Belo Horizonte: UFMG, s./d. Disponível em: <http://www.eeffto.ufmg.br/>. Acesso em: 27/01/2014.

Sites:

$\langle$ http://aplicacao.saude.gov.br/plataformabrasil/login.jsf >

Recebido em: 25-04-2014.

Aprovado em: 25-05-2014 